Georgia State University ScholarWorks@ Georgia State University

Geosciences Faculty Publications

Department of Geosciences

1976

\title{
Real Estate Agents and Geographical Information
}

Risa Palm

Georgia State University, risapalm@gsu.edu

Follow this and additional works at: http://scholarworks.gsu.edu/geosciences_facpub

Part of the Geography Commons, and the Geology Commons

\section{Recommended Citation}

Palm, Risa. 1976. "Real Estate Agents and Geographical Information". Geographical Review 66 (3): 266-80. doi:10.2307/213885.

This Article is brought to you for free and open access by the Department of Geosciences at ScholarWorks @ Georgia State University. It has been accepted for inclusion in Geosciences Faculty Publications by an authorized administrator of ScholarWorks@ Georgia State University. For more information, please contact scholarworks@gsu.edu. 


\section{REAL ESTATE AGENTS AND GEOGRAPHICAL INFORMATION*}

\section{RISA PALM}

A SUBSTANTIAL empirical literature on intra-urban mobility has accumulated over the past ten years. In these studies, the city or metropolitan area is considered to be the "whole" within which such descriptors as directional bias, sectoral patterns, distance bias, and search space are applied. However, the specification of the whole defines the nature and valence of its parts: ${ }^{1}$ the assumption that the urban area acts as the whole within which mobility behavior takes place gives rise to patterns, generalizations, and even descriptions of behavior that may differ from those which would be derived from another framework. Any structuralfunctional analysis of mobility requires the specifications of its frame, and any behavioral study must ensure that this frame be behaviorally meaningful to the persons involved in the process under study. To study mobility from a behavioral perspective, it is thus essential to specify the nature of the geographical information field. ${ }^{2}$ Only with an understanding of this field, the frame within which further selection and decision making takes place, can we proceed to order and describe the migration decision.

The purpose of this paper is to demonstrate that even in a relatively homogeneous, medium-sized metropolitan area there is no single information field. Not one but many information spaces, sometimes overlapping, sometimes disjunct, operate even for households with equivalent means and preferences. The thesis herein is that the metropolitan area cannot be considered as a whole within which individuals choose locations. Even if the home buyer makes use of those information sources that should provide the broadest and least spatially biased sources of information-real estate agencies who are members of the Multiple Listing Service ${ }^{3}$ - he is exposed to only a small portion of the market in any price range.

\footnotetext{
*The author wishes to express thanks to Douglas J. Caruso, who shared in the research design and in the collection and processing of the Minneapolis data. Substantial advice and assistance were provided by John S. Adams, John R. Borchert, Anita Caruso, W. A. V. Clark, D. E. Greenland, R. J. Johnston, and A. R. Pred. Acknowledgement is made of the financial assistance provided by the Pennsylvania State University New and Visiting Faculty Research Grant and by the Committee on Research of the University of California, Berkeley.

${ }^{1}$ F. Lukermann: Geography: De Facto or De Jure, Journ. Minnesota Acad. of Sci., Vol. 32, 1965, pp. $189-196$.

${ }^{2}$ Peter Gould: Acquiring Spatial Information, Econ. Geogr., Vol. 51, 1975, pp. 87-99.

${ }^{3}$ The Multiple Listing Service is a cooperative listing service conducted among a group of member realtors. A member company that accepts a listing promises to turn it over to a central bureau, from which it is distributed to all members who then have the right to sell the property. Commissions are divided between the selling office and the listing office, with a small percentage returned to the MLS office itself. We were informed that the particular agreement among the Minneapolis realtors at the time of the survey was that if the property was sold "within house," 25 percent of the commission went to the listing agent, 35 percent to the selling agent, and 40 percent to the broker. If the property was sold by another broker, the commission was divided evenly among the brokers, and the brokerage commission was divided so that 57.50 percent went to the selling agent, 27.50 percent to the listing agent, 0.25 percent to the Multiple Listing Service, and the remainder to the broker. A study of the sales of used single-family residences in Oakland, California, during 1968 showed no significant differences in the values of homes sold through the Multiple Listing Service and other sales. See Boris W. Becker: On the Reliability of Multiple Listing Service Data, The Appraisal fournal, Vol. 40, 1972, pp. 264-267.
}

Dr. Palm is an assistant professor of geography at the University of California, Berkeley, California 94720 . 


\section{Home Buyers and Their Information Sources}

The household seeking to purchase a single-family detached house searches for particular characteristics of the housing unit, such as number of rooms, style of the dwelling unit, age of the unit, and landscaping. ${ }^{4}$ In several surveys recent buyers were asked to evaluate the importance of such features in their purchase decision, and answers were found to vary by the respondent's income and sex. ${ }^{5}$ The household also has to make a decision about the location of the house, involving such factors as tax rates, reputation of local schools, and distance from shopping, relatives, or place of work. The potential home buyer thus seeks a wide variety of information, not all of which can be obtained through direct observation. Although the means by which the household gains information about the house itself is of interest, we shall focus on the ways in which potential buyers obtain information about the area in which the house is located. We shall concern ourselves not with the home-buying decision itself, but rather with constraints on the information frame within which the purchase decision is made.

For many people, the choice of area is affected by an information network that is strongly influenced by family ties, ethnic group membership, previous experience with the neighborhood, or information from friends and colleagues. Other people are more dependent on formal or public sources of information, including newspaper advertisements, on-site notices, and real estate agency files. For example, a third of the approximately 32,000 people sampled in a recent survey by the National Opinion Research Center (NORC) claimec that they had used such public information sources as real estate agencies and newspaper advertisements to find their current residence, and another third said that friends, relatives, and co-workers had been their most important information source ${ }^{6}$ A perhaps surprising similarity in the use of various information sources exists across socioeconomic classes and ethnic groups: when responses were stratified into four socioeconomic categories and four ethnic or racial categories, there was less than 5 percent difference in the use of each of the information sources, with the exception of newspaper advertisements (used less frequently by blacks and by Spanish-s peaking persons).

Empirical work on mental maps of urban areas and on the nature of spacesearching behavior provides strong inferential evidence that households do not possess a very large portion of the total available information about existing vacancies. ${ }^{7}$ Tuan has suggested that research findings on spatial images may not be related to an

${ }^{4}$ Donald J. Hempel: A Comparative Study of the Home Buying Process in Two Connecticut Housing Markets (Center for Real Estate and Urban Economic Studies, Univ. of Connecticut, Storrs, Conn., 1970).

5 "Buyers Profile Analysis of Factors Relating to the Home Buying Decision" (School of Bus. Admin., Calif. State Polytech. Coll., Pomona; Calif. State Dept. of Real Estate, Sacramento; 197ı).

${ }^{6}$ Personal communication from Elihu Gerson, National Opinion Research Center, Chicago, Ill., Feb. 14, 1973 .

${ }^{7}$ J. S. Adams: Directional Bias in Intra.Urban Migration, Econ. Geogr., Vol. 45, 1969, pp. 302-323; Lawrence A. Brown and Eric G. Moore: The Intra-Urban Migration Process: An Actor-Oriented Approach, Geografiska Annaler, Vol. 52B, 1970, pp. 1-13; D. J. Caruso: Neighborhood Search, Residential Evaluation and the Housing Market (Ph.D. dissertation in progress, Dept. of Geography, Univ. of Minnesota, Minneapolis); W. A. V. Clark: A Test of Directional Bias in Residential Mobility, in Perspectives in Geography I, Models of Spatial Variation (edited by Harold McConnell and David Yaseen; Northern Illinois Univ. Press, De Kalb, Ill., 1971), pp. 1-27; B. Donaldson: An Empirical Investigation into the Concept of Sectoral Bias in the Mental Maps, Search Spaces and Migration Patterns of Intra-Urban Migrants, Geografiska Annaler, Vol. 55B, I973, pp. 13-33; R. J. Johnston: Urban Residential Patterns (Praeger, New York, 1971), pp. 293-329; and K. W. J. McCracken: Household Awareness Spaces and Intraurban Migration Search Behavior, Professional Geogr., Vol. 27, 1975, pp. I66-1 70. 
understanding of spatial behavior. ${ }^{8}$ In any case, further work will be required if we are to understand the ways in which people use the information that is available to them. But for the moment we may turn our attention to the overall limitations on the availability of information. In other words, although individual choices are interesting to study, they are difficult to specify and perhaps less useful for planning purposes than the nature of the overall constraints on human choice. ${ }^{9}$

Home buyers have a limited amount of time and resources which they are willing to expend in their search for a house. They must continually reevaluate the options of choosing from the information they have at hand or of possibly losing a "bird in the hand" as the house they have tentatively settled on is sold to someone else while they continue their search. Lease expiration dates, problems of timing and financing the coordination of buying a home while selling a previous home, or the excessive costs of living in a hotel while looking for a permanent home in a new city may further constrict the search. Furthermore, some houses never reach the general market. We are probably all familiar with stories of the exchange of homes among university faculty members who never consult real estate agents at all, or homes that are sold through exclusive listings of highly localized, possibly foreign-language-speaking realtors who advertise through local community newspapers to a foreign-language group only. Thus, even with unlimited amounts of time and other resources, the total vacancy picture can never be fully comprehended.

In general, information that purchasers may consider necessary for an optimum practical decision is scattered in such places as real estate company files, newspapers, on-property "for sale" signs, and personal contacts. The greatest constraints in information face newcomers to the city who lack access to private information sources. The information source that should be most complete is the large, multibranched realty office, subscribing to a metropolitan-area-wide Multiple Listing Service (MLS) and perhaps affiliated with one of the several intercity realty company chains. This source should not be spatially biased in the sense of systematically excluding listings in low-income or nonwhite areas. ${ }^{10}$ Therefore one may expect that as a single information source, large, MLS-affiliated realty companies show the least territorial or price bias in representing the housing market. It is this kind of agency that provides us with a portrait of the most complete information readily available to the home buyer from a single source. If we can demonstrate that these real estate agents are not providing information on the entire city, but instead are focusing on systematically selected segments of the housing market, we will conclude that the entire metropolitan area cannot be considered as a whole in the home selection process and that structural-functional statements such as those about directional bias must be redefined.

\section{The Real Estate Agent as Information Source}

The role of the realtor as a source of information in the home purchase process has been studied chiefly through survey research. In some studies, recent movers have

${ }^{8}$ Yi-Fu Tuan: Images and Mental Maps, Annals Assn. of Amer. Geogrs., Vol. 65, 1975, pp. 205-213.

9 Torsten Hägerstrand (The Domain of Human Geography, in Directions in Geography [edited by Richard J. Chorley; Methuen and Co., Ltd., London, 1973], pp. 67-87) presents a cogent argument for analyzing constraints on human behavior rather than investigating preferences which are already environmentally constrained.

${ }^{10}$ Boris William Becker: Selected Economic Aspects of Real Estate Brokerage (unpublished Ph.D dissertation, Dept. of Business Administration, Univ. of California, Berkeley, 1970). 
been asked to list those sources of information they consulted during the move process and to evaluate the relative importance of each source ${ }^{11}$ Other studies have attempted to isolate the type of information that real estate agents provide to home buyers ${ }^{12}$ and the methods agents use to encourage or discourage buyers from considering particular neighborhoods. ${ }^{13}$ Survey information exists on the proportions of persons who consult with real estate agents and on their evaluations of the importance of agents on their final decision. In general, newcomers to the city, especially those who have come to the city because of job transfers, are highly dependent on the real estate agent as an information source. ${ }^{14}$ The less familiar the mover is with the metropolitan area, the more dependent he is on the agent for information, not only on the location of vacancies but also on the desirability of various neighborhoods. This dependence is affected by the length of the search, as well as by the previous experience of the home buyer with using real estate agents in the home purchase process. ${ }^{15}$

Well-meaning real estate agents may intentionally or even unintentionally provide information that limits the search of prospective buyers by advising clients on the social character of neighborhoods and on the likelihood of property resale. Although most agents do not provide so blatant a social evaluation of parts of the city, the newcomer may be assaulted with printed literature even as he arrives at the metropolitan airport:

So the "good" residential areas extended South and a little West from the loop (by the river)-First Lowry Hill, then Kenwood-Lake of the Isles....Edina is one of the very logical places for newcomers. There is usually quite a little turnover. Making new friends in Edina is easy-many other "new" families are also seeking, and the constant come-and-go keeps the community fairly uncliquish. ${ }^{16}$

One has no doubt that if the newcomer follows the advice of the pamphlet and contacts this well-established realty firm he will get quite definite guidance on which areas of the city are best for his family and for their life-style. Not even the best tourist guidebook or most careful social geography of a city will provide the newcomer with as many opinions about communities that are or are not "appropriate."

The membership of a real estate office in the Multiple Listing Service should in some ways offset the local effects of company territoriality on agents' views. Each member company is provided with specifications of houses for sale in all price brackets and in all areas of the city in which member companies sell houses. Although the agent may still be tempted to sell his own company listings first (to enjoy a greater commission), he should at least be aware of listings in all parts of the city. Ideally,

${ }^{11}$ Donald J. Hempel: The Role of the Real Estate Broker in the Home Buying Process (Center for Real Estate and Urban Economic Studies, Univ. of Connecticut, Storrs, Conn., 1969); D. T. Herbert: The Residential Mobility Process: Some Empirical Observations, Area, Vol. 5, 1973, pp. 44-48; and Frank A. Barrett: Residential Search Behavior, York Univ. Research Monographs, No. I, Toronto, 1973

${ }^{12}$ Hempel, Role of the Real Estate Broker [see footnote I I above].

${ }^{13}$ Charles M. Barresi: The Role of the Real Estate Agent in Residential Location, Sociol. Focus, Vol. I, 1968, pp. 59-71; and Stuart H. Palmer: The Role of the Real Estate Agent in the Structuring of Residential Areas: A Study in Social Control (unpublished Ph.D. dissertation, Dept. of Business, Yale Univ., New Haven, Conn., 1955).

${ }^{14}$ Caruso, op. cit. [see footnote 7 above]; and Hempel, Role of the Real Estate Broker [see footnote II above].

${ }^{15}$ Becker, Real Estate Brokerage [see footnote ro above].

16 "What's it Like to Live in Minneapolis?" (Rees, Thomson, Scroggins, Inc., Minneapolis, n.d.) 


\section{MEDIAN VALUE OF HOUSING, MINNEAPOLIS, 1970}

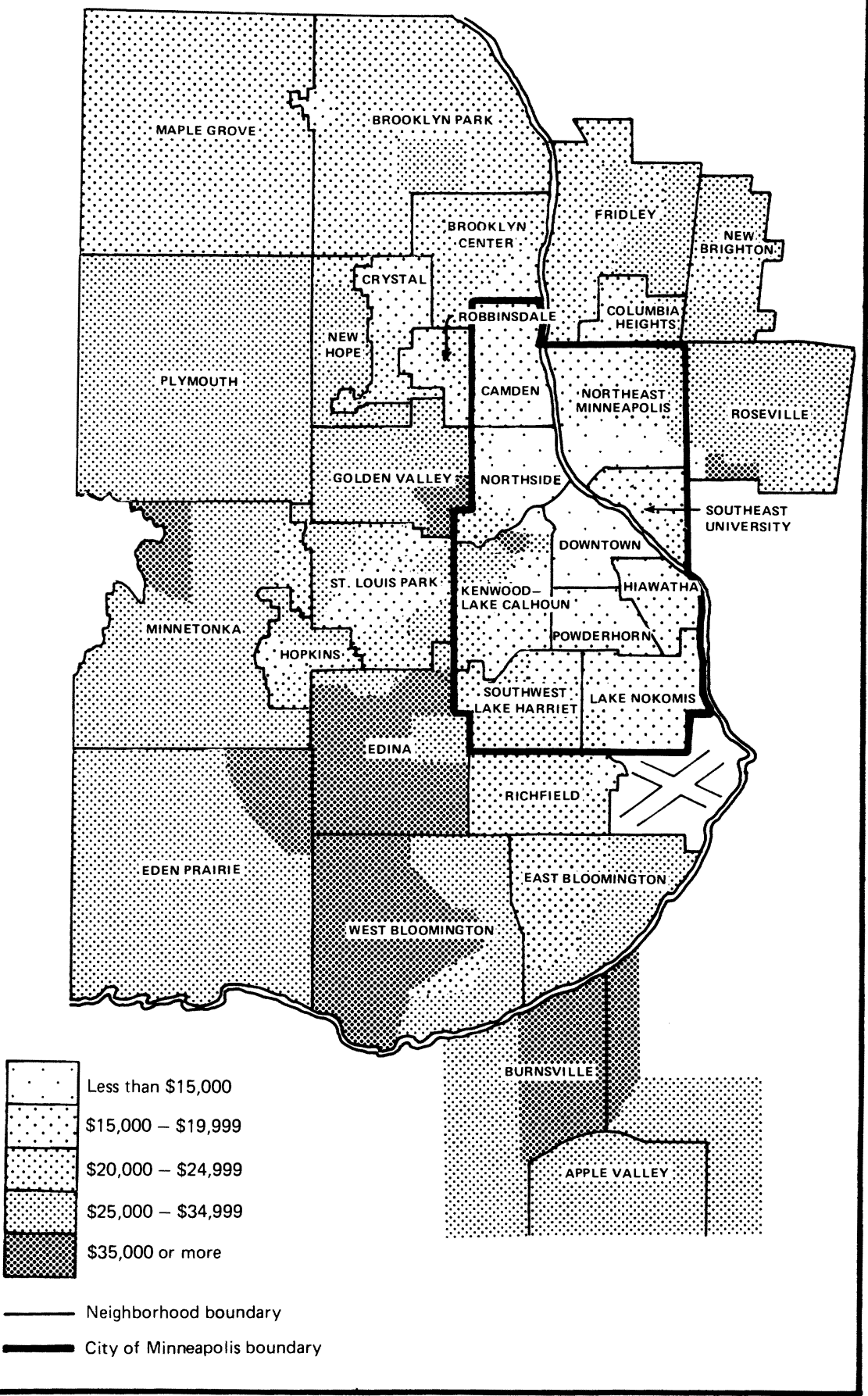

FIG. 1-Median value of housing, Minneapolis, 1970. Compiled from data in the United States Census of Population, Census Tracts, 1970. 
and what we might call his awareness space should coincide with the limits of the areas governed by his board of realtors.

To confirm the thesis that even real estate agents affiliated with the largest realty companies and associated with the Multiple Listing Service have limited knowledge and biased opinions of local areas within the metropolitan area, three hypotheses were tested: that realty companies cover limited parts of the housing market in their listings; that the overall evaluations of realtors correspond to the actual vacancy pattern; and that individual real estate agents vary significantly in their evaluations of areas "appropriate" for certain types of home buyers, an evaluation which is associated with market territorialization. In other words, an attempt was made to ascertain the limits of information, especially the local variances one might find from the aggregate picture.

\section{The Minneapolis Study}

Minneapolis, Minnesota, and its suburbs were selected as the study area. St. Paul and its suburbs were excluded from this study on the grounds that its residential housing market operates in an independent fashion despite its proximity to Minneapolis. ${ }^{17}$ In addition, by limiting the study to Minneapolis and its suburbs, we could ignore the very real barriers to information flow imposed by two competing sets of realty boards.

Minneapolis is a particularly good study area because of its structural simplicity. Its housing stock is distributed according to the classic (Chicago) model of regular accretions of new housing around the central business district, and socioeconomic groups are arranged sectorally. ${ }^{18}$ Areas of upper-income residence have traditionally focused on the lakes to the west and southwest of the central business district, at present including parts of the Kenwood neighborhood within Minneapolis and parts of the suburbs of Golden Valley, Edina, Minnetonka, and West Bloomington (Fig. 1). Low-income areas spread from the near north and near south sides of the central city to the flat countryside to the north and south of the city, including Columbia Heights, Crystal, Robbinsdale, and parts of Richfield. The central business district has maintained itself as a focus of office and business activity, making it a plausible employment center for persons in a variety of occupational classes. Although the Mississippi River divides the city north of the central business district, relatively few sharp physical breaks or climatic contrasts interrupt the settlement pattern or add to its complexity. Moreover, the population is fairly homogeneous in ethnic structure, permitting us to set aside, to a large extent, questions of the effects of the predominance of a particular ethnic or racial group in a local neighborhood on realtor evaluations of that area. Because this structural simplicity makes Minneapolis an excellent laboratory for testing such concepts as directional bias and sectoral

\footnotetext{
${ }^{17}$ Richard Hartshorne (The Twin City District: A Unique Form of Urban Landscape, Geogr. Rev., Vol. 22, 1932, pp. 431-442) observed the functional independence of the two cities in shopping behavior, travel patterns, and support of cultural events. Hildegard Binder Johnson (An Introduction to the Geography of the Twin Cities [Dept. of Geography, Macalester College, St. Paul, Minn., 1970]) elaborated on this theme in noting the separate newspapers, television stations, and real estate advertisements in the two cities. Finally, even intracity telephone call frequencies in a toll-free area show substantial independence (see Risa Palm: The Concept of Community: A Geographical Perspective [unpublished Ph.D. dissertation, Dept. of Geography, Univ. of Minnesota, Minneapolis, 1972]).

${ }^{18}$ John S. Adams: Residential Structure of Midwestern Cities, Annals Assn. of Amer. Geogrs., Vol. 6o, 1970, pp. $37-62$.
} 
structure, it should also be an excellent test case for measuring the range of the geographical information field.

\section{MARKET COVERAGE}

The first hypothesis was that even the largest realty companies vary in the degree to which their listings are representative of the price range and areal extent of the actual vacancy surface. A 20 percent stratified random sample was drawn of all houses listed for sale by the thirty-eight largest member companies of the Minneapolis Board of Realtors. Each of the companies studied was a member of the Multiple Listing Service, and three of them were affiliated with national intercity relocation offices. This list of houses for sale in early August, 1973, was a sample of approximately 70 percent of all the houses offered for sale through the Multiple Listing Service at that time. ${ }^{19}$ The offices of the thirty-eight companies studied were located throughout Minneapolis and its suburbs (Fig. 2). The locations of houses for sale were plotted, and a mean center and a standard deviation ellipse were calculated for the listings for each agency. ${ }^{20}$

Listings for the largest companies showed variation in areal coverage and in average price and price specialization (Table I). Areal coverage was approximated by measuring the area included within the standard ellipse. These areas varied from 2.7 square miles to 94.8 square miles, although it must be noted that these sizes were distorted by the uneven spatial distribution of the listings. Variation in the extent to which listings were localized within sectors of the city was estimated with a rough index of directional bias, the extent to which the listings were circular or linear in areal distribution (the ratio of the length to the width of the standard deviation ellipse). Coverage varied from almost circular (index of approximately 1.00) to strongly linear (index of 7.67). The relationship between the size of the area covered by real estate company listings and the extent to which coverage was circular $\left(r_{s}=-0.15\right)$ was weak. This absence of association indicates great variation in the sizes and patterns of company sales areas.

Agencies also showed marked variation in price specialization. Some companies specialized either in high-priced or in low-priced homes, and others handled a variety of price classes. The mean price of houses listed by the companies ranged from $\$ 17,700$ to $\$ 67,800$. In addition, the within-company variance in prices of house listings, indexed by a coefficient of variation (standard deviation/mean price), ranged from 0.96 to 0.18 . There was a fairly strong inverse relationship between size of the area covered by the listings and price specialization as indexed by the price coefficient of variation $\left(r_{s}=0.63\right)$, and also between number of listings (company size) and price specialization $\left(r_{s}=0.60\right)$. There was little association, however, between average price and price specialization $\left(r_{s}=0.28\right)$, indicating that those companies which listed higher-priced houses tended to be no less specialized than those which listed lowerpriced houses. The average price of houses listed was positively related to the areal

19 There were more than the usual number of houses for sale during this particular period than there would usually be in the late summer, because of a shortage of mortgage money. However, this should not distort the pattern of house listings for particular companies, nor should it affect the results of the survey, except to emphasize the territorial patterns of real estate company coverage.

${ }^{20}$ The standard (deviation) ellipse has been widely used as a measurement of spatial dispersion, and is described in Roberto Bachi: Standard Distance Measures and Related Methods for Spatial Analysis, Papers Regional Sa. Assn., Vol. 10, 1963, pp. 83-132; and Lawrence A. Brown and John Holmes: Intra-Urban Migrant Lifelines: A Spatial View, Demography, Vol. 8, 1971, pp. 103-122. 


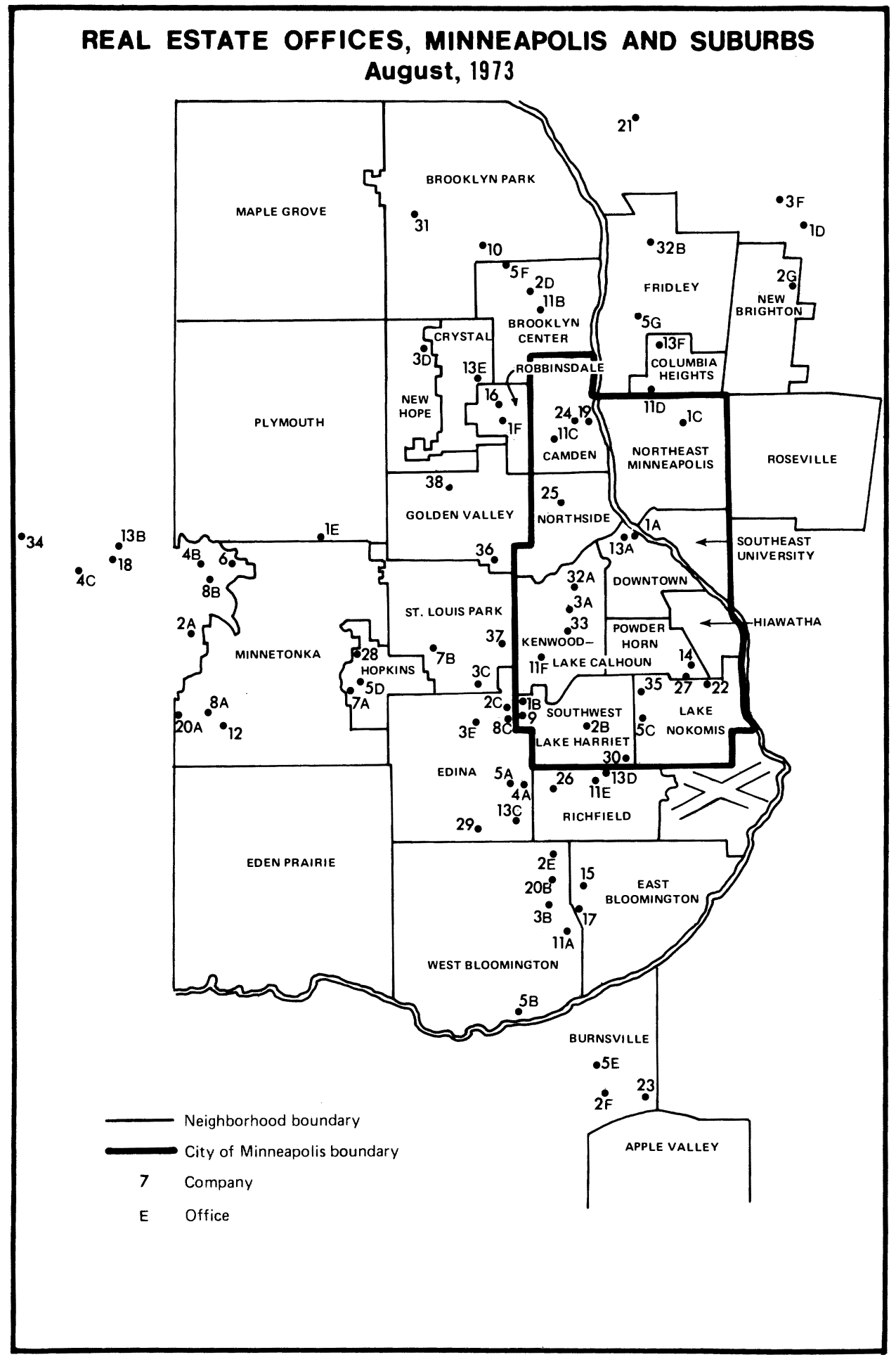

FIG. 2-Real estate offices, Minneapolis and suburbs, August, 1973. Source: Minneapolis Telephone Directory. 
Table I-Market Coverage of Minneapolis Realtors

\begin{tabular}{|c|c|c|c|c|c|}
\hline COMPANY & $\begin{array}{l}\text { NUMBER OF } \\
\text { LISTINGS }\end{array}$ & $\begin{array}{c}\text { AREA OF } \\
\text { COVERAGE } \\
\text { (in square miles) }\end{array}$ & $\begin{array}{l}\text { DIRECTIONAL BIAS } \\
\text { OF LISTINGS } \\
\text { (length of main } \\
\text { axis in standard } \\
\text { ellipse/width) }\end{array}$ & $\begin{array}{l}\text { MEAN PRICE } \\
\text { OF LISTINGS }\end{array}$ & $\begin{array}{l}\text { PRICE-COEFFICIENT } \\
\text { OF VARIATION } \\
\text { (standard devia- } \\
\text { tion/mean price) }\end{array}$ \\
\hline 1 & 110 & $5^{8 \cdot 3}$ & 1.79 & $\$ 49,100$ & 0.96 \\
\hline 2 & 305 & $5^{1.2}$ & 1.37 & 40,600 & 0.55 \\
\hline 3 & 110 & $39 \cdot 9$ & 1.07 & 37,300 & 0.45 \\
\hline 4 & 115 & 94.8 & 1.58 & 39,700 & 0.63 \\
\hline 5 & 385 & 45.2 & 1.06 & 48,000 & 0.65 \\
\hline 6 & 80 & 17.5 & 1.05 & 55,600 & 0.50 \\
\hline 7 & 115 & 18.1 & 1.93 & 39,600 & $0.4^{1}$ \\
\hline 8 & 135 & $33 \cdot 3$ & 2.00 & 67,800 & $0.9^{2}$ \\
\hline 9 & 80 & 39.8 & 1.14 & 36,900 & 0.39 \\
\hline 10 & 170 & 30.2 & 1.16 & 29,100 & 0.36 \\
\hline II & 265 & $3^{6.7}$ & 2.00 & 28,700 & 0.55 \\
\hline I 2 & 115 & 20.0 & 2.13 & 37,100 & $0.3^{6}$ \\
\hline 13 & 135 & $5^{6.2}$ & 1.85 & 33,500 & 0.75 \\
\hline 14 & 36 & 7.0 & 1.00 & 20,200 & 0.41 \\
\hline 15 & 19 & 13.3 & 1.25 & 45,000 & 0.18 \\
\hline 16 & 14 & 2.7 & 1.00 & 28,700 & 0.31 \\
\hline 17 & 13 & $7 \cdot 9$ & 1.90 & 27,400 & 0.34 \\
\hline 18 & 11 & 50.7 & $2.5^{2}$ & 29,100 & 0.49 \\
\hline 19 & 10 & 16.8 & 2.39 & 23,900 & 0.30 \\
\hline 20 & 40 & 38.9 & 1.38 & 39,400 & 0.55 \\
\hline 21 & 14 & I 4.4 & 1.53 & 31,600 & 0.26 \\
\hline 22 & 21 & 41.2 & 2.05 & 23,300 & 0.33 \\
\hline 23 & 50 & 46.7 & 1.03 & 36,500 & 0.49 \\
\hline 24 & 39 & 11.4 & 2.27 & 21,900 & 0.34 \\
\hline 25 & 20 & 2.7 & 1.83 & 17,700 & 0.28 \\
\hline 26 & 39 & 27.9 & 1.34 & 30,000 & 0.45 \\
\hline 27 & 26 & 29.9 & 2.39 & 21,000 & 0.49 \\
\hline 28 & 12 & 11.5 & 7.67 & 47,500 & 0.35 \\
\hline 29 & 28 & 31.4 & 1.12 & 28,200 & $0.4^{8}$ \\
\hline 30 & 31 & 13.9 & 2.33 & 23,700 & 0.38 \\
\hline 31 & 26 & 21.0 & 2.57 & 26,100 & 0.30 \\
\hline $3^{2}$ & 25 & $45 \cdot 4$ & 1.62 & 23,900 & 0.60 \\
\hline 33 & 15 & 19.3 & $\mathrm{I} .8 \mathrm{I}$ & 25,600 & $0.4^{6}$ \\
\hline 34 & 21 & 15.0 & 3.60 & 29,400 & 0.49 \\
\hline 35 & 33 & 17.2 & 1.28 & 24,700 & 0.72 \\
\hline 36 & $5^{6}$ & $33 \cdot 7$ & 1.11 & 34,400 & 0.53 \\
\hline 37 & 11 & 21.0 & 1.55 & 30,500 & 0.33 \\
\hline $3^{8}$ & 16 & 34.9 & 2. 10 & 31,200 & 0.31 \\
\hline
\end{tabular}

Source: Calculated from information in Multiple Listing Service files.

size of company coverage $\left(r_{s}=0.40\right)$ and to the total number of listings the company had during the study period $\left(r_{s}=0.5 \mathrm{I}\right)$. We can conclude that real estate agents had widely varying direct contact spaces, in the sense that some handled listings throughout the urban area while others dealt with a territory little larger than a single census tract.

The effects of real estate company specialization on home-buying behavior are difficult to specify without studying the consumers themselves. Nevertheless, it is clear that there is great variation in the so-called awareness space of the realty agents and that potential home buyers, and certainly newcomers to the city who are dependent on real estate agents for information, will find themselves dealing initially with a highly variable information market, limited by the nature of the real estate company with which they happen to make contact first.

\section{EVALUATIONS OF NEIGHBORHOODS BY AGENTS}

If agents are to act as sources of information without a spatial bias, it must be assumed that they provide buyers with essentially similar evaluations of the character of 
neighborhoods. Any deviation from this relative homogeneity in the provision of information must be seen as a second, and perhaps even more important, constraint on the information set of the home buyer.

Evaluations of neighborhoods were elicited from more than 250 realtors, at least five and as many as ten from each of the thirty-eight largest companies. The questionnaire consisted of a schematic map of Minneapolis and its suburbs, divided into typical real estate districts compiled from a composite of newspaper real estate want ad divisions and planning department delimitations of community areas. Eight hypothetical families, each headed by a male who worked in the central business district, and whose occupation was selected from one of four positions along a composite of occupation status rating scales, were to be matched with these districts. In each of the hypothetical families the female spouse was a housewife not employed outside the home. Each social status was represented by two families at different stages in their life cycle: one childless and one with two children of school age. The realtors were directed to indicate one or more areas of the city where they, as agents for their companies, would advise such families to look for a home to buy.

Considering all agents together, recommendations to each of the family types corresponded remarkably well with the current pattern of vacancies at appropriate price ranges, inasmuch as this pattern could be reconstructed from the locations of houses advertised for sale in the classified advertisements of the Sunday newspaper and from the total listings available from the Multiple Listing Service (Fig. 3). Agents seemed to have no difficulty in and virtually no objection to responding to a questionnaire in which they were provided with a minimum of information about a family and were asked to recommend any number of neighborhoods to them. The highest degree of consensus, not surprisingly, centered on those neighborhoods most appropriate for upper-income households. But in all price ranges the recommendations of all of the realtors taken together and the pattern of houses offered for sale showed considerable coincidence.

More than half of all the realtors recommended Golden Valley, Edina, West Bloomington, and Minnetonka to the highest status family, that of the dentist. The distribution of houses for sale priced over $\$ 60$, 000 also shows a concentration in Minnetonka, Edina, Golden Valley, and West Bloomington, with a scattering in the notrecommended Plymouth.

Recommendations to the hypothetical family at the second highest socioeconomic status position, that of the accountant, converged on Edina and Golden Valley, with West Bloomington added for the family without children. Houses advertised for sale in the $\$ 46,000-\$ 60$,oon range (using the real estate rule of two and a half times the yearly income as a suitable home value) are located in these areas and also in Minnetonka, recommended by fewer of the realtors for this family type. Other areas with houses for sale in this price bracket but which received few recommendations include Eden Prairie, Plymouth, Richfield, Lake Nokomis, and some of the northern suburbs. Realtors seem to favor the southwestern suburbs here, to the disadvantage of areas within the city limits (such as the Lake Nokomis area) and north of the city.

St. Louis Park was recommended for the bookkeeper, a good choice in view of the distribution of houses for sale in the $\$ 24,000-\$ 28$, o00 price range. The scatter of houses in this price bracket in East Bloomington, Richfield, Southwest-Lake Harriet, Crystal, and Robbinsdale is reflected in the agreement of a smaller number of realtors on these as appropriate areas. Northeast, Camden, and Brooklyn Center were omitted, however, again reflecting a general bias in favor of the southern and western suburbs. 


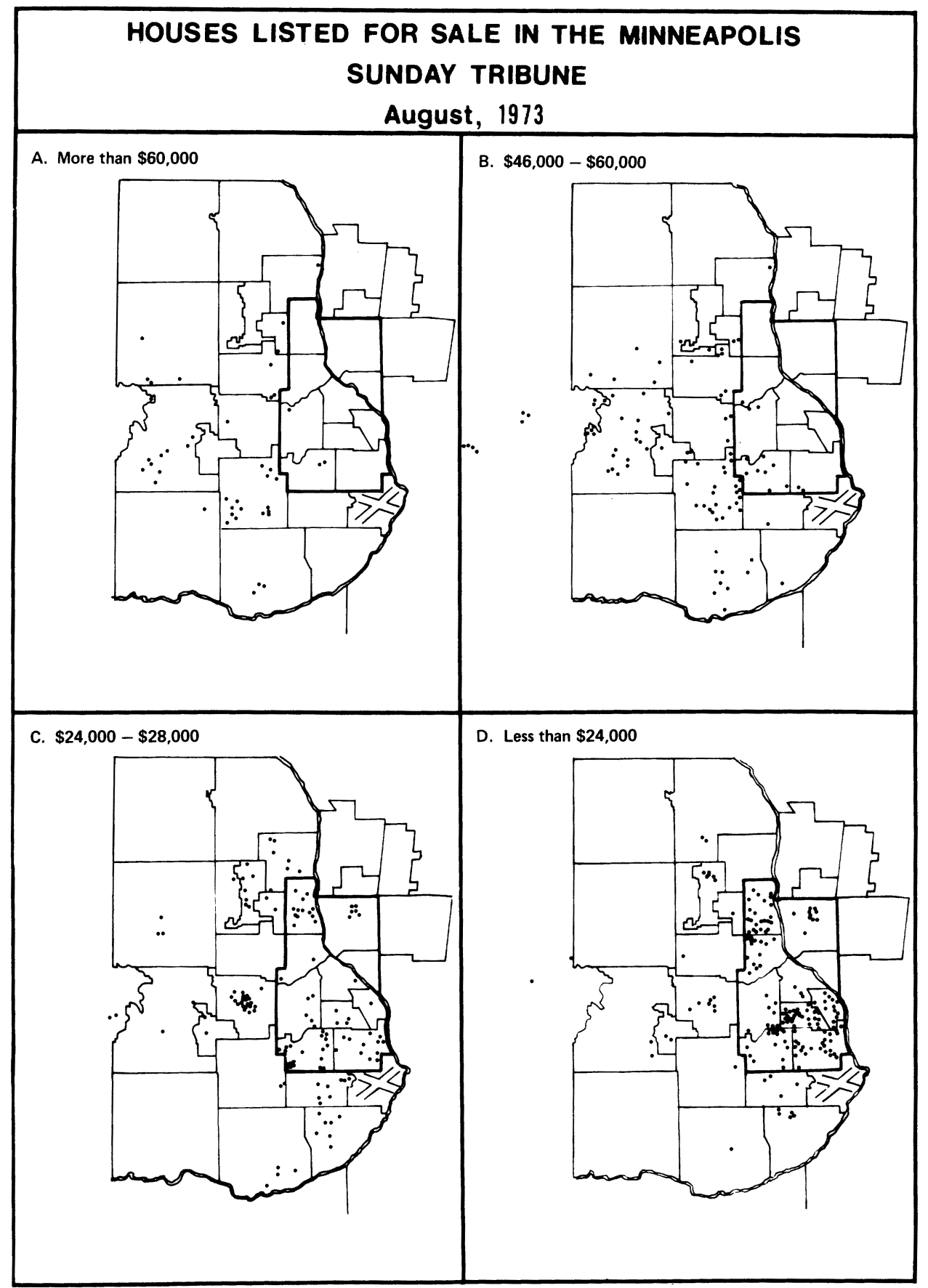

Fig. 3-Houses listed for sale in the Minneapolis Sunday Tribune during the month of August, 1973. 
A variety of areas were recommended to the family of lowest socioeconomic status. To the deliveryman's family, the North Side was most frequently recommended, followed closely by Northeast, Powderhorn, and Hiawatha. These areas, however, accounted for only a small portion of the areas with houses for sale for less than $\$ 24,000$, which included, in addition, Camden, St. Louis Park, Southwest-Lake Harriet, Lake Nokomis, Richfield, and East Bloomington.

In sum, there was substantial concordance in the overall pattern of realtor recommendations and in the locations of houses for sale at corresponding price ranges. We might conclude, then, that realtors do provide a substantially accurate picture of the vacancy surface in their recommdations to families of various incomes. But people do not visit "all realtors taken together"; rather, they deal with one or perhaps two agencies in their search for a home. It is thus important to view the information field from the perspective of recommendations by individual companies.

REAL ESTATE AGENTS' VIEWS OF THE URBAN AREA

Deviation from the overall association between areas recommended by realtors and location of houses for sale within an appropriate price range is considerable when one focuses on recommendations made by realtors from individual companies. For example, some realtors recommended that the high-income dentist move to areas near the inner city or to the northeastern suburbs, and some realtors recommended that the low-income deliveryman move to Edina or to West Bloomington.

To assess the strength and nature of individual company recommendation patterns, a matrix of "expected" neighborhood frequencies per company was constructed against which observed frequencies could be compared. Expected frequencies were computed based on the proportion of total responses recommending the particular neighborhood. ${ }^{21}$ An expected cell entry was computed for each of the thirty-eight companies, for thirty-two neighborhoods, for each of the eight family types. To assess the extent to which the location of company listings was associated with the overrecommendation of a neighborhood, a matrix of observed minus expected frequencies was calculated. ${ }^{22}$

The pattern of individual areas strongly overrecommended is clearly local. Realtors within companies have a strong tendency to recommend areas close to their offices and their own company listings, regardless of the social class or family status of the hypothetical family (Fig. 4). Of the seventeen companies strongly recommending neighborhoods to the dentist, fourteen recommended neighborhoods in which the company had houses for sale. Thirteen of fourteen companies overrecommeded local areas to the accountant, and fourteen of seventeen recommended local areas to the deliveryman and to the bookkeeper. It should be emphasized that the survey presented the realtors with hypothetical families to be matched with hypothetical

${ }^{21}$ For example, if there were 1,000 total responses in which realtors recommended some of the thirty-two neighborhoods to a given type of family and if Company A accounted for 100 of these responses, we would expect Company A to account for 10 percent of the responses for each of the neighborhoods. If Neighborhood 1 were recommended 50 times, Company A would be expected to have made 5 of those recommendations, and the 5 would be entered in the cell for Neighborhood 1, Company A. Similarly, if Neighborhood 2 were recommended 70 times, Company A would be expected to have provided 7 of these recommendations. Each cell entry was thus computed for each of the companies and each of the neighborhoods.

${ }^{22} \mathrm{An}$ area was classed as overrecommended if it had a score of 2.0 or more; in other words, if it received at least two more than the expected number of recommendations it was considered to be overrecommended. 
housing opportunities. Unlike the situation which realtors confront in attempting to satisfy actual customers, there was no economic incentive to recommend areas or houses within the realty company territory, for there was no commission to be gained or lost from their recommendations. We cannot, therefore, explain the localized view of the realtors in terms of mere financial self-interest, but rather must consider these patterns of responses to be actual reflections of realtors' knowledge and opinions of various areas of the city. Furthermore, of all Minneapolis agents, it was these who should have had the broadest view of the availability of housing, since they were employed by the largest, most well-connected agencies, all of which were members of the Multiple Listing Service.

\section{The Hypotheses Confirmed}

There is positive evidence to confirm each of the hypotheses. First, realty companies do cover limited portions of the housing market in both price and area. Areal coverage varies from those companies that list houses in a single neighborhood to those with branches throughout the urban area that list houses in large portions of the metropolitan area. No single company covers the entire metropolitan area, however. Similarly, price coverage varies from those companies that specialize in high-priced or low-priced houses to those that list houses in all price brackets.

Second, the overall evaluations of realtors taken together provide a generally accurate portrayal of the houses listed for sale throughout the metropolitan area, inasmuch as this can be reconstructed from a combination of Multiple Listing Service and newspaper information. Exceptions to this general statement occur in an underevaluation of the northern sector of the city and an overevaluation of the western and southwestern sectors by all realtors taken together. The pattern of underevaluation or overevaluation of particular areas of the city does not seem to be related to the relative numbers of houses for sale, the turnover rate, or the relative quality of houses in these areas. Indeed, many of the housing developments in Brooklyn Center, New Hope, and Plymouth were constructed and sold by the same companies that built up large portions of West Bloomington, Burnsville, and Eden Prairie. Rather, it seems that the description by developers and realtors of the southern and southwestern suburbs as highly mobile areas with rapidly increasing house prices has become a self-fulfilling prophecy; overevaluation by realtors and developers leads to an increase in demand, the upward bidding of prices, rapid sales, and a further round of relative increases. The realtor evaluations are, in fact, reflected in the relative costs of housing: often the "same" houses, constructed by the same firms, and with the same apparent amenities, have prices that vary as much as $\$ 10,000$ to $\$ 20,000$.

Third, individual agents show marked differences in their evaluations of those neighborhoods that are most appropriate for certain types of home buyers. When agent responses are considered by company, one notes a clear pattern of overrecommendations for neighborhoods in which company offices are located and in which the company has listings. Real estate agents have a tendency to bias their recommendations in favor of the territories with which they are most familiar, giving a strong local effect to the pattern of neighborhood recommendations. Thus not only the buyers but also the real estate agents have limited awareness spaces. It is no doubt true that these limitations in agents' views of the city have some effect on the decisionmaking process of the home buyer with respect to the neighborhood on which he focuses his search. 


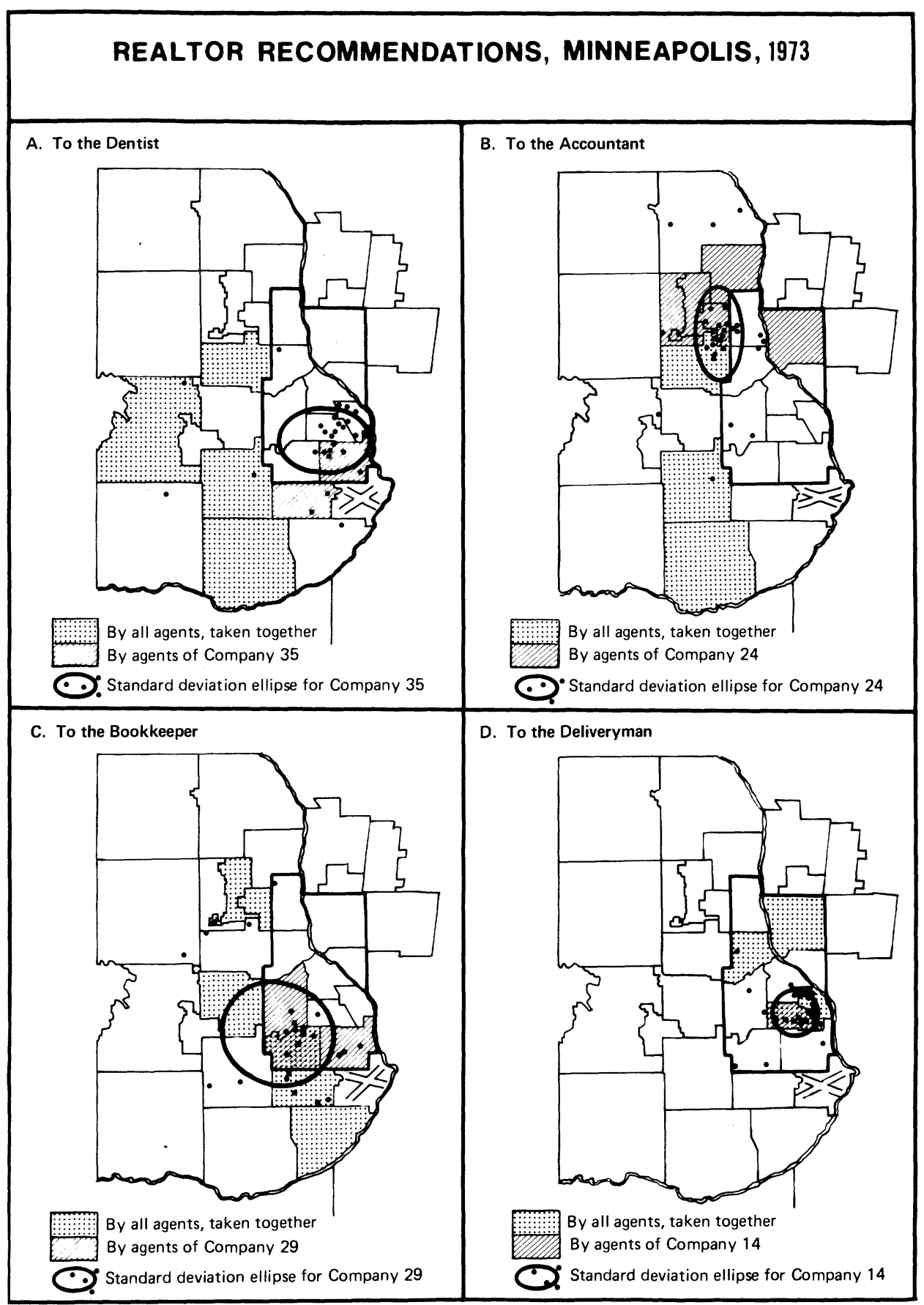

Fig. 4-Examples of recommendations by individual companies that "overrecommended" their local territories. Those areas recommended by "all agents taken together" represent areas recommended by at least 35 percent of all the respondents. Overrecommendations for selected companies are indicated, with the listings which that company offered for sale during August, 1973, and along with a generalized estimate of company territory (the standard deviation ellipse). 
The information surface of even those professionals who are involved on a daily basis in the sale of property and who have connections with similar sales agents throughout the metropolitan area is localized, falling far short of covering the entire urban area. That such localization prevails in a relatively homogeneous urban area must lead us to suspect that a discontinuous pattern of information sets is even more prevalent in larger and more physically complex metropolitan areas, which are frequently even further segmented by separate and competing boards of realtors.

The home buyer finds himself in an even more limited situation. Since he is one step removed from an already incomplete informational whole, he inevitably is constrained to an even smaller portion of the information available, as biases and filters simplify information about housing vacancies and neighborhoods.

The description of the city in terms of metropolitan-wide patterns of rings, wedges, sectors, or an overall directional bias in spatial behavior is logically linked to the view that the metropolitan area constitutes a behavioral whole. When one considers the set of housing opportunities as filtered through restrictions on information, this whole appears to be arbitrarily bounded, for it has been defined by such criteria as commuting patterns and residential densities and not directly linked to the set of housing opportunities which a potential migrant considers in his decision to move.

If there is no single geographical information field, there is no common and continuous territory in which intra-urban migration as a process of geographical knowledge acquisition and decision making can be discussed. In this sense directional bias becomes meaningless; although there is no doubt that moves may occur within a limited portion of the city, we cannot logically establish a directional pattern to these moves if we do not have agreement on a behaviorally meaningful, common territory which we are dividing into directions. Similarly, we cannot divide the urban pie into wedges or rings of opportunities unless we can first specify that there is a single, common, geographical information pie to divide. As in the familiar problem of the delimitation of regions, we must give attention to the effects of bounding some area for study on the results of subsequent analysis. ${ }^{23}$ In the present case, we have little reason to believe that the metropolitan area constitutes a ready-made region within which locational information is evenly available. Informational wholes should be delimited empirically, and with a specific purpose in mind.

Geographers need to heed Peter Gould's plea for a return to the exploration and mapping of new spaces and landscapes of the information environment. ${ }^{24}$ We should not, then, merely assume the formulation of awareness spaces within which moves, tautologically, take place. We cannot understand the landscape of knowledge about place merely by asking questions about the places people visit or recognize. Rather, we must seek to discern how people learn about places and focus our attention on institutions that facilitate or limit access to geographical information.

\footnotetext{
${ }^{23}$ Fred Lukermann: Empirical Expressions of Nodality and Hierarchy in a Circulation Manifold, East Lakes Geogr., Vol. 5, 1969, pp. 17-44.

${ }^{24}$ Gould, op. cit. [see footnote 2 above]. F. Lukermann recently argued (in "The History and Philosophy of the Science," Assn. of Amer. Geogrs. Minicourse, Milwaukee, Wisc., April, 1975) that geography has moved from the study of objects and things that can be directly apprehended, to the study of sense data, instruments, and concepts (the "external world of the Structural Realist and the Logical Empiricist"), to its current emphasis on "a world of phenomenal appearances filtered through a subjective world of experience," in which the focus of study is "the act of perception and the behavior it stimulates." If this conceptualization of the field does indeed reflect current research concerns, then it follows that the apprehension of "phenomenal appearances," the study of how people come to learn about and understand the experienced environment, is a central research theme.
} 